\title{
Probabilistic Projections of Anthropogenic Climate Change Impacts on Precipitation for the Mid-Atlantic Region of the United States*
}

\author{
LiANG NiNG AND MichaEl E. MANN \\ Department of Meteorology, and Earth and Environmental Systems Institute, The Pennsylvania State University, \\ University Park, Pennsylvania \\ ROBERT CRANE \\ Department of Geography, The Pennsylvania State University, University Park, Pennsylvania \\ THORSTEN WAGENER \\ Department of Civil and Environmental Engineering, The Pennsylvania State University, University Park, Pennsylvania \\ RAYMOND G. NAJJAR JR. \\ Department of Meteorology, The Pennsylvania State University, University Park, Pennsylvania

\section{RIDDHI SINGH} \\ Department of Civil and Environmental Engineering, The Pennsylvania State University, University Park, Pennsylvania
}

(Manuscript received 30 September 2011, in final form 19 January 2012)

\begin{abstract}
This study uses an empirical downscaling method based on self-organizing maps (SOMs) to produce highresolution, downscaled precipitation projections over the state of Pennsylvania in the mid-Atlantic region of the United States for the future period 2046-65. To examine the sensitivity of precipitation change to the water vapor increase brought by global warming, the authors test the following two approaches to downscaling: one uses the specific humidity in the downscaling algorithm and the other does not. Application of the downscaling procedure to the general circulation model (GCM) projections reveals changes in the relative occupancy, but not the fundamental nature, of the simulated synoptic circulation states. Both downscaling approaches predict increases in annual and winter precipitation, consistent in sign with the "raw" output from the GCMs but considerably smaller in magnitude. For summer precipitation, larger discrepancies are seen between raw and downscaled GCM projections, with a substantial dependence on the downscaling version used (downscaled precipitation changes employing specific humidity are smaller than those without it). Application of downscaling generally reduces the inter-GCM uncertainties, suggesting that some of the spread among models in the raw projected precipitation may result from differences in precipitation parameterization schemes rather than fundamentally different climate responses. Projected changes in the North Atlantic Oscillation (NAO) are found to be significantly related to changes in winter precipitation in the downscaled results, but not for the raw GCM results, suggesting that the downscaling more effectively captures the influence of climate dynamics on projected changes in winter precipitation.
\end{abstract}

* Supplemental information related to this paper is available at the Journals Online website: http://dx.doi.org/10.1175/JCLI-D-1100565.s1.

Corresponding author address: Liang Ning, Department of Meteorology, The Pennsylvania State University, University Park, PA 16802. E-mail: lun115@psu.edu

\section{Introduction}

Warming over the next century associated with anthropogenic increases in greenhouse gas concentrations is likely to be especially large over North America (Meehl et al. 2007). State-of-the-art general circulation models (GCMs) project that annual mean precipitation over North America is likely to increase in association 
with the consequent enhancement of atmospheric moisture (Christensen et al. 2007).

Although GCMs are the major tools used for future climate projections because of their well-established physical basis and ability to reproduce observed features of recent climate, particularly at continental and larger scales (Randall et al. 2007), GCMs cannot adequately resolve many important processes needed to capture regional climate changes, such as convective and topographically forced precipitation. Yet capturing such details is crucial for climate change impact studies at decision-making scales (Barron 2009) and for the estimation of relevant hydrologic variables such as streamflow or soil moisture (Wagener et al. 2010). To bridge the gap between the GCMs and regional climate change, two types of downscaling methods have been developed and widely applied (Houghton et al. 2001; Christensen et al. 2007). One such approach, dynamical downscaling, uses regional climate model (RCM) simulations (Chen et al. 2003; Plummer et al. 2006), while the alternative approach involves so-called statistical or empirical downscaling.

In this paper we describe an application of empirical downscaling of daily precipitation over multiple locations in Pennsylvania (United States). The objective is to estimate future projections that can be used to drive hydrological and ecological models while employing a new approach to ensemble averaging, and to explore the uncertainty of these projections. Uncertainty exists in GCM projections of future climate largely because of the uncertainty in the projected anthropogenic forcing itself (i.e., the emissions scenario considered or "scenario uncertainty"), intermodel differences in the physical parameterization of subgrid-scale processes, and because of random variability and the dependence on initial conditions (see, for example, Maraun et al. 2010). Similar sources of uncertainty are found to dominate RCM projections (e.g., Rowell 2005; Rowell and Jones 2006). Frei et al. (2003) also conclude that deficiencies in the parameterizations for convection, the soil physics and land surface parameters, and the surface radiation balance are possible RCM error sources on simulations of daily precipitation statistics over European Alps. The sensitivity of projected midtwenty-first-century climate changes is relatively insensitive to the scenario uncertainty (Fig. 10.4, Meehl et al. 2007); the spread in the projected global surface temperature increase through 2050 is only about $1^{\circ} \mathrm{C}$. It is thus reasonable to select, as in this study, one representative scenario and focus instead on the physical uncertainties in projected future climate change.

Much of these physical uncertainties arise from the characteristically low resolution and varying physical parameterizations of subgrid-scale processes (radiative transfer, cloud formation, convection, etc.) in the different GCMs analyzed (Meehl et al. 2007; Christensen et al. 2007). Downscaling can potentially circumvent, at least partly, the influence of such limitations on projections of daily precipitation. One caveat is that impacts from factors such as future land cover changes and the distribution of aerosols complicate efforts to downscale projected climate change to regional scales. Empirical downscaling does not reduce these additional scenario uncertainties (although, with dynamical downscaling it is at least possible to examine the local sensitivity to these parameters).

Benestad (2002b) uses a multimodel ensemble method to evaluate the results of empirical downscaling of different global climate scenarios and different regions. $\mathrm{He}$ finds that the ensemble spread provides a crude measure of the uncertainties associated with different scenarios and that different models show a reasonably strong level of agreement for projected winter temperature changes. Benestad (2004) also finds that a downscaling analysis of a multimodel ensemble can provide a first estimate for a probabilistic climate forecast, despite the large differences among climate scenarios and among GCMs. Hewitson and Crane (2006) also show that empirical downscaling can help to reduce the uncertainty arising from different GCM parameterization schemes. In this paper, we will present how the downscaling method can reduce the inter-GCM uncertainties on future projected annual and seasonal precipitation changes.

Moreover, to assess the performance of downscaling methods in reducing uncertainty following the idea of Benestad (2002a), we examine the changes of downscaled precipitation and related synoptic circulation North Atlantic Oscillation (NAO), which is the most prominent mode of atmospheric variability in the Northern Hemisphere winter climate (Wallace and Gutzler 1981; Barnston and Livezey 1987) and a major source of seasonal to interdecadal climate variability on winter surface temperature, storminess, and precipitation over the northern Atlantic and European regions (Deser 2000; Thompson and Wallace 2001; Wanner et al. 2001; Trenberth et al. 2007; Miettinen et al. 2011).

Because of the poleward expansion and weakening of the Hadley Circulation and a poleward shift of the storm tracks, sea level pressure (SLP) is projected to increase over the subtropics and midlatitudes and decrease over high latitudes as greenhouse gas concentrations increase in most models (Yin 2005). Combined with other dynamical mechanisms related to the vertical structure of atmospheric temperature changes resulting from elevated greenhouse gas concentrations (e.g., Miller et al. 2006), these responses generally lead to projections of a 
positive trend in the NAO across models (Meehl et al. 2007).

Many studies have shown that the NAO has a strong influence on regional temperature and precipitation variability over Europe (Hurrell 1995; Rodó et al. 1997; López-Moreno and Vicente-Serrano 2008). However, there are only a few studies addressing the influence of the NAO on precipitation patterns in North America, especially the Northeast United States (Hurrell et al. 2003). In this paper, we investigate the relationship between winter precipitation over Pennsylvania and the $\mathrm{NAO}$ and use model-projected changes in the NAO as a means of classifying and understanding some of the spread observed in the downscaled estimates of projected precipitation change.

\section{Data and methodology}

\section{a. Data and downscaling procedure}

The study area Pennsylvania locates at mid-Atlantic region of the United States, and the locations of 17 stations used in this paper are shown in Fig. 1. The observed precipitation data for the 17 stations are for the period 1961 to 2005. The empirical downscaling scheme used here is described briefly below and in detail in Ning et al. (2012). The downscaling procedure employed here uses self-organizing maps (SOMs) to define the characteristic modes of the synoptic-scale atmospheric state centered on each of the points (meteorological stations) for which the downscaling takes place. SOMs are analogous to a fuzzy-clustering algorithm and are usually used to visualize and characterize multivariate data distributions (Kohonen 1989, 1995). A SOM is typically depicted as a two-dimensional array of nodes, where each node is described by a vector representing the average of the surrounding points in the original data space. For an input dataset that is described by a matrix of $n$ variable data points and $m$ observations, each node in the SOM is described by a reference vector having length $n$. The initial step in the SOM training involves assigning random values to each node reference vector, and then comparing the data record with each node vector. The reference vector that most closely matches the data vector is defined as the "winning" node. Then the reference vector of the winning node is updated slightly toward the direction of the input data by a factor termed the "learning rate." All the surrounding nodes are also updated in the direction of the input data by a smaller learning rate. The entire process is then repeated for multiple iterations until the differences between iterations are smaller than a selected threshold value. This training procedure is described in detail in

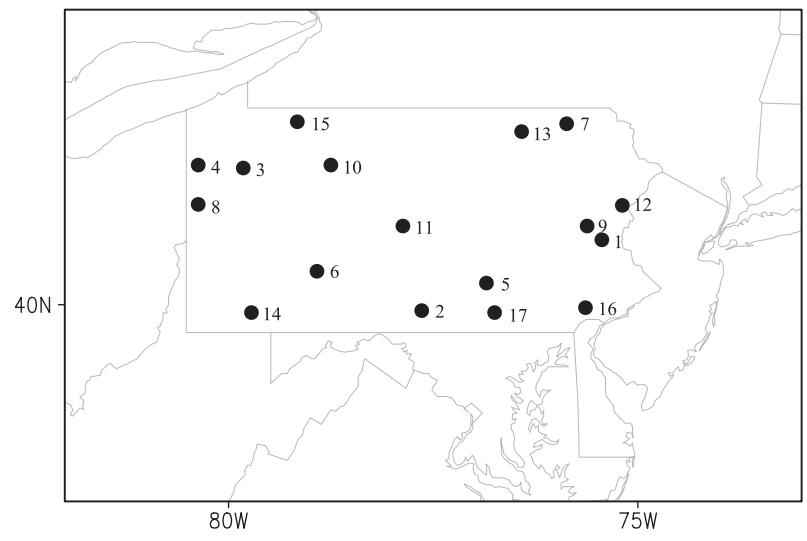

FIG. 1. Map of Pennsylvania and the surrounding region, indicating the locations of the 17 stations used in the study. The names of the stations are listed in Table 2 .

Crane and Hewitson (2003). In the training step, all the seven or eight variables (see descriptions below) from the National Centers for Environmental Prediction (NCEP) reanalysis data for period 1979-2007 are used to generate the SOM.

Then for each station, we compare the observed daily atmospheric data to the SOM nodes and map each day to one particular node. For each SOM node, we take all the days that map to that particular node and then rank the precipitation on those days from low to high. A spline is fit to the ranked precipitation data to define a continuous cumulative distribution function (CDF) of the node's rainfall. This procedure is repeated for all the nodes in the SOM and then for all stations. In the downscaling procedure, each day's atmospheric state from present or future simulations of the GCMs is mapped to a node on the SOM, and a precipitation value is selected from the CDF of that node through the random number generator.

For a more detailed discussion of the downscaling procedure, and results for historical [twentieth-century climate in coupled models $(20 \mathrm{c} 3 \mathrm{~m})$ Coupled Climate Intercomparison Project phase 3 (CMIP3) multimodel] simulations, the reader is referred to our previous work (Ning et al. 2012). During the historical period, our downscaling approach was shown to reproduce the major characteristics of the observed precipitation with smaller biases than the raw GCM-simulated precipitation. Here we apply the downscaling procedure to the 2046-2065 simulations using the $\mathrm{A} 2$ emissions scenario for the same nine GCMs of the CMIP3 multimodel ensemble that were used for the historical period ('20c3m') analysis in Ning et al. (2012): Canadian Centre for Climate Modelling and Analysis (CCCma) Coupled General Circulation Model, version 3.1 (CGCM3.1), Centre National de Recherches 
Météorologiques Coupled Global Climate Model, version 3 (CNRM-CM3), Commonwealth Scientific and Industrial Research Organisation Mark version 3.0 (CSIRO Mk3.0), Geophysical Fluid Dynamics Laboratory Climate Model version 2.0 (GFDL CM2.0), Goddard Institute for Space Studies Model E-R (GISS-ER), L'Institut Pierre-Simon Laplace Coupled Model, version 4 (IPSL CM4), Meteorological Institute of the University of Bonn, ECHO-G Model (MIUBECHOG), Max Planck Institute (MPI) ECHAM5, and Meteorological Research Institute Coupled General Circulation Model, version 2.3.2a (MRI CGCM2.3.2a). To assess the sensitivity of future precipitation projections to the way in which changes in atmospheric humidity are represented, we try two downscaling approaches in this paper. The first approach uses seven variables: $u$ and $v$ components of the wind at $10 \mathrm{~m}$ and $700 \mathrm{hPa}$, relative humidity at $850 \mathrm{hPa}$, air temperature anomaly at $10 \mathrm{~m}$, and the lapse rate of temperature from 850 to $500 \mathrm{hPa}$. In the second approach, the specific humidity at $850 \mathrm{hPa}$ is added as an eighth variable to capture the water vapor increase brought by global warming.

Comparisons with an ensemble of RCM simulations over South Africa suggested that in some locations the use of specific humidity overestimated future rainfall change (B. C. Hewitson 2009, personal communication). The rationale for including specific humidity is that increasing temperatures in the future could increase the potential for rain without changing relative humidity. Under present-day conditions, downscaling over Pennsylvania with and without specific humidity gives essentially the same result (Ning et al. 2012). Downscaling future climate projections, however, shows a significant difference. A range of input variables were tested prior to selecting the seven variables described in the original derivation of the methodology applied to South Africa by Hewitson and Crane (2006). In this paper, therefore, we do not examine the uncertainty that results from including or excluding all combinations of input variables, but we do examine the differences that arise from including specific humidity as an additional humidity parameter.

\section{b. Ensemble averaging through skill-based weighting}

In this paper, we employ a new weighting method for constructing multimodel ensemble weighted-average monthly precipitation amounts from the individual downscaled model estimates, modified from a procedure introduced by S. Carter (2007, personal communication) for South Africa. Calculating a weighted average based on the skill with which each GCM is able to recreate historical conditions is one option for producing a single time series from an envelope of ensemble projections (Brekke et al. 2008). The assumption is that models that do well under the present climate will also do well in the future. In this paper we introduce a modification of the weighted average, accepting that with no better information to go on, the models that have higher skill in the present should be given greater weight in the future. However, we also consider that the relative skill exhibited by a particular model is not likely to be the same under all conditions, such as the large-scale atmospheric flow responsible for frontal rainfall and small-scale convection. The averaging method described here takes such variability into account.

The proposed method works as follows. During the downscaling procedure, each day's simulated atmospheric state is mapped to one of the characteristic synoptic states defined by the nodes in the SOM. As noted above, the SOM can be considered analogous to a nonlinear fuzzy clustering algorithm, where each node in the SOM describes a cluster of points in the original multidimensional data space. For each node (or cluster) there is a corresponding quantization error defined by the distribution of points (days) that form the cluster. The quantization error is the sum of the absolute differences of each day from the group mean (analogous to the within group variance in cluster analysis). Larger quantization errors indicate greater variability between the days mapped to a particular node. The advantage of this approach is that it gives greater weight to those GCMs with simulations closer to the characteristic synoptic circulation and the weighting for each model changes each day as the atmospheric state changes. This approach can generate a closer ensemble average to the observation than the simply averaging method for the historical period.

To produce an ensemble weighted-average daily precipitation amount, we first calculate the total quantization error from all GCMs for each day. We apply that quantity as a normalized inverse weight for that day's downscaled daily precipitation amount for each GCM and sum over the GCMs to obtain an ensemble averaged daily precipitation amount. The weighted ensemble average precipitation, $\bar{p}$, is given by

$$
\bar{p}=\sum_{i=1}^{9}\left(\begin{array}{c}
\frac{\sum_{i=1}^{9} e_{i}}{e_{i}} \\
p_{i} \frac{\sum_{i=1}^{9} e_{i}}{\sum_{i=1} \frac{1}{e_{i}}}
\end{array}\right)
$$

where $p_{i}$ is the downscaled daily precipitation for that day from the $i$ th $\mathrm{GCM}$, and $e_{i}$ is the corresponding quantization error for that day from that GCM. 
After generating the ensemble averages across all nine GCMs, the inter-GCM uncertainty is defined as the root-mean-squared deviation from the ensemble average for each precipitation metric. The same approach is used to compute the weighted ensemble average for both present and future conditions. The quantization error for the future projection shows how closely the simulation maps to the present atmospheric states, but the weighting also takes into account how the frequency of occurrence of those states changes in the future, thus the weighting of each GCM may actually change between the present and the future as changes occur in the simulation of the synoptic atmospheric conditions.

\section{Results}

\section{a. Simulated future changes of the synoptic states}

Figures $2 \mathrm{a}-\mathrm{i}$ show the differences in frequency distributions of characteristic synoptic-scale atmospheric states between the midtwenty-first-century (2046-2065) and late twentieth-century modern control (1961-2000) periods for the nine GCMs, for the Harrisburg station $\left(40^{\circ} \mathrm{N}, 76.5^{\circ} \mathrm{W}\right)$, located in central Pennsylvania. The results shown correspond to the first of the two downscaling schemes (i.e., without specific humidity). Similar results are obtained using the second "dual humidity" scheme wherein specific humidity is used as well as relative humidity. The $11 \times 9$ matrix represents the SOM, where each cell in the matrix represents a characteristic synoptic atmospheric state composing seven circulation variables. The figure shows the percent difference in how many days map to each atmospheric state in the future compared to the present. Considering all days of the year (i.e., all seasons simultaneously), we see that for the majority of GCMs most of the substantial changes in frequency are found in the interior nodes of the SOM. When applying the averages plus/minus the standard deviations as significant thresholds, only $20 \%-30 \%$ of the nodes have significant changes for different GCMs. This observation suggests that the climate for this region is characterized by the same basic range of atmospheric states. The projected changes in climate, then, are largely represented through the shifts in the frequency of existing synoptic atmospheric states, rather than through the creation of new, nonanalog states. Downscaling based on the SOM derived from present-day observations of the atmospheric state should thus be broadly valid for the projection of future changes.

Large increases in frequency at the edges of the SOM, if combined with large increases in the quantization error (Figs. 2j-r) on the same nodes might, on the other hand, indicate problems with stationarity (i.e., the future climate being so different to the present that it is trying to map beyond the bounds of the SOM). The GCMs simulated present and future daily synoptic circulation state datasets should be considered as two data spaces. When the future synoptic circulation state data are mapped to the characteristic circulation patterns representing the present synoptic circulation state data, if the future synoptic circulation data are very different from the present synoptic circulation data, the SOM will have the tendency to map the days to the edges of the SOM, which are the bound of the present data space. Meanwhile, the quantization errors over the edges of the SOM will also be much larger since the future data spaces have much greater distances from the characteristic patterns than the present data space. Our results, however, show little evidence of such a problem and only about $10 \%-30 \%$ of the changes significant, with two notable exceptions: the IPSL and CSIRO Mk3.0 models. The IPSL model shows a reduction in quantization error across the whole SOM. This suggests that while the IPSL simulation of future climate includes the same range of atmospheric states, there is less variability around those states than exists in the present-day simulation. CSIRO Mk3.0, on the other hand, shows increased quantization errors on some nodes, and much reduced errors on others. This suggests that the future simulation exhibits a reduced range of states, but with increased variability around each state. Although it manifests itself in different ways, both models are showing reduced variability in atmospheric conditions in the future.

Figure 3 shows the differences in quantization errors between the two periods averaged across all (99) SOM nodes, with their corresponding standard deviations, for each of the nine GCMs. With the notable exception of CSIRO Mk3.0 and IPSL, the differences are indistinguishable from zero, reinforcing the conclusion that circulation states in the future map similarly close to their associated nodes for the present.

\section{b. Projections of future precipitation (GCM versus downscaled results)}

\section{1) Changes in ANNUAL PRECIPITATION}

Table 1 compares downscaled and raw simulated changes from late twentieth to midtwenty-first century in average monthly precipitation amounts and number of rain days for each of the nine GCMs for the Harrisburg station. Only daily precipitation totals that meet the standard definition of a "rain day" (larger than $0.25 \mathrm{~mm}$, i.e., 0.01 inch-see Fitzpatrick and Krishan 1967; Hershfield 1971; Gallus and Segal 2004) are considered. Results are shown for the raw GCM projections as well as for the two downscaling methods. 

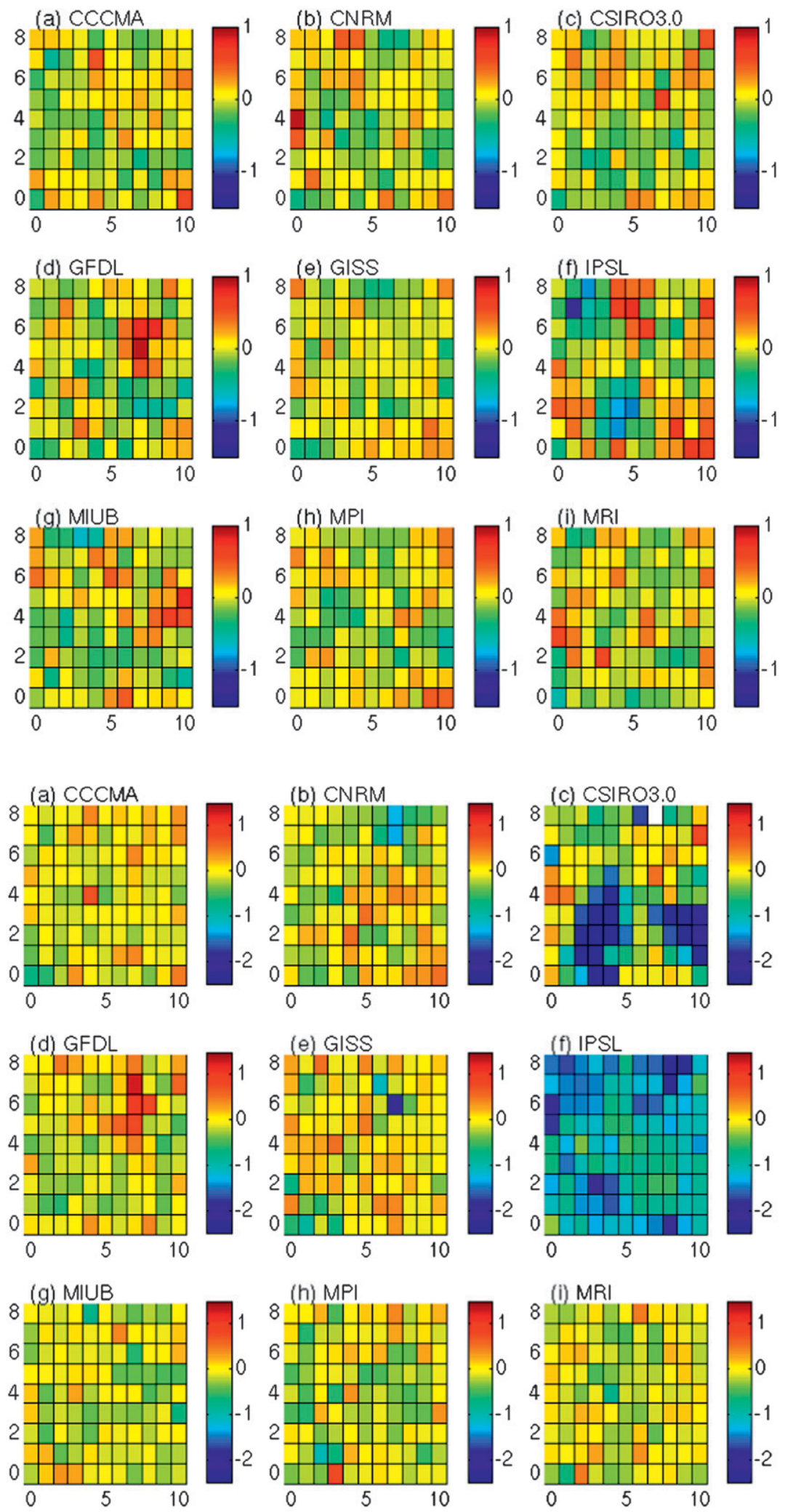

FIG. 2. (a)-(i) The differences of frequency distributions (unit: \% change) and (j)-(r) quantization error differences (unit: 1) between the future (2046-65) and control (19612000) climate simulations centered on $\left(40^{\circ} \mathrm{N}, 76.5^{\circ} \mathrm{W}\right)$ for the nine GCMs. 


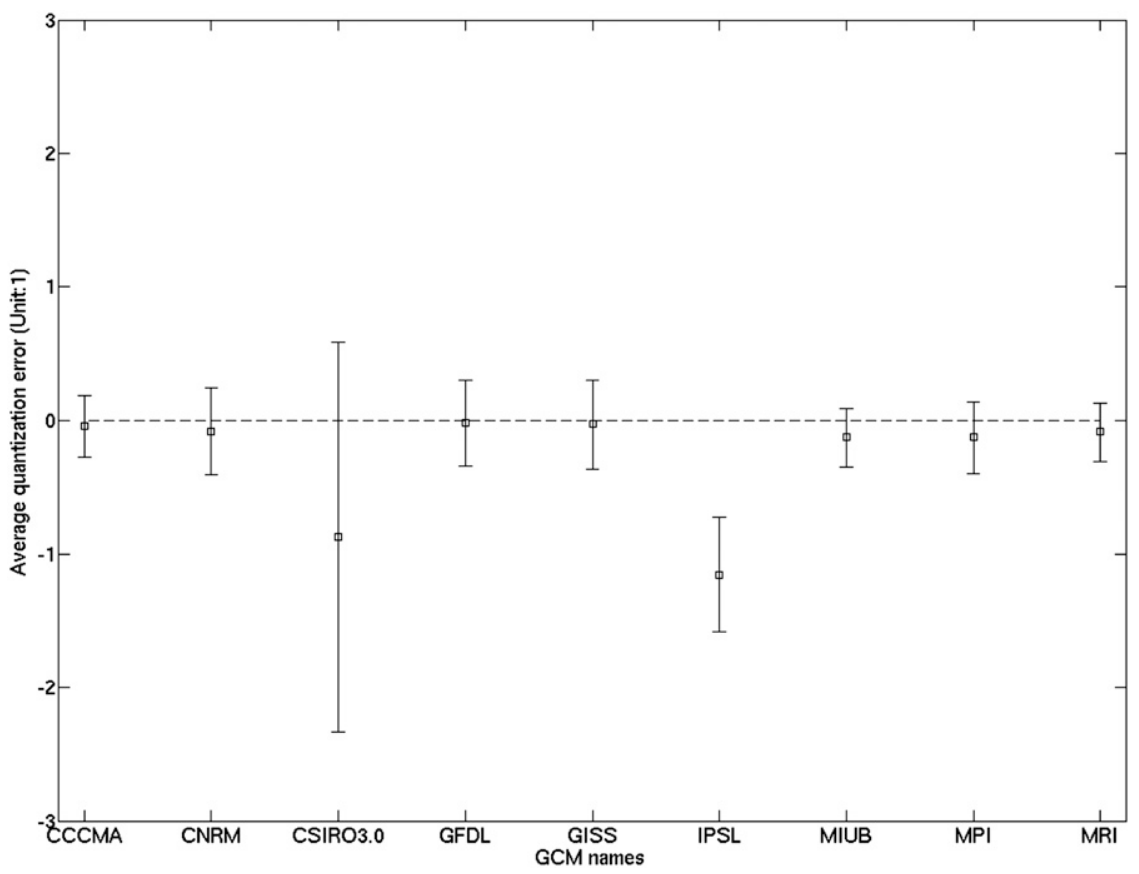

FIG. 3. The values of quantization error differences averaged across all 99 nodes (squares) and standard deviations (whiskers) for the nine GCMs (unit: 1).

For the downscaled precipitation based on the first method (relative humidity only), changes in monthly average precipitation range from roughly $-3 \mathrm{~mm}$ to $+9 \mathrm{~mm}$, with an ensemble average $+2.7 \mathrm{~mm}$. All GCMs show small (less than 1 day) changes in the average monthly rain day totals, with an average of +0.2 days, considering both the observed and downscaled average monthly numbers of rain days are about 11 days. Using the second method (dual humidity variables), monthly average precipitation increases are larger, ranging from +0.6 to $+8.7 \mathrm{~mm}$, with an ensemble average of $+3.1 \mathrm{~mm}$, while the change in mean monthly rain day totals is identical (average of +0.2 days over models). For the raw model-simulated precipitation, increases are larger than those for either downscaling approach, with an ensemble averaged increase of $+6.5 \mathrm{~mm}$. The change in rain day totals $( \pm 1$ day) remains small, though the nominal number of rain days is already greatly overestimated (about 20 days per month) by the GCMs for the modern day control-see Ning et al. (2012). Note that the intermodel variability, defined as the standard deviation, is much larger for the raw GCM changes than for either of the two downscaling-based estimates.

There is no consistent pattern between the three sets of results in Table 1 across models. For CCCMA, the projected change in precipitation is essentially the same for the raw GCM estimates and both downscaling estimates. For CNRM, the downscaling with both humidity values increases the projected rainfall change and moves it closer to the raw GCM values. For CSIRO Mk3.0, on the other hand, using both humidity parameters reduces the projected increase and reduces agreement between the downscaling and raw model values. However, for six out of the nine models, using both humidity parameters enhances the precipitation increase in the future since including specific humidity will take the future water vapor increase into account and tend to increase the precipitation probability in the downscaling procedure. For two models, the changes switch from negative to positive, and only in one case does it reduce the future change. Overall, the standard deviation of future projections is much greater for the raw GCM values than it is for either of the downscaling results.

\section{2) SPATIAL VARIATION}

Figures $4 \mathrm{a}-\mathrm{f}$ show the spatial distribution of changes in precipitation and rain days for the ensemble average across the nine GCMs over all months. The corresponding percentages and GCM consensus of precipitation changes are shown in Fig. S1 (http://dx.doi.org/10.1175/JCLI-D-1100565.s1.). For the downscaling without specific humidity (Fig. 4a), decreases are found over northwest Pennsylvania, while increases are found over southeast Pennsylvania. This pattern of gradual increase from northwest to southeast also exists in the downscaled changes with dual 
TABLE 1. The changes of the downscaled and simulated average monthly precipitation amounts and average monthly numbers of rain days between the future period (2046-65) and historical period (1961-2000) from nine GCMs over station Harrisburg.

\begin{tabular}{lrrrrrr}
\hline \hline GCM names & DA $^{\mathrm{a}}$ & $\mathrm{DN}^{\mathrm{b}}$ & $\mathrm{DAB}^{\mathrm{c}}$ & $\mathrm{DNB}^{\mathrm{d}}$ & $\mathrm{SA}^{\mathrm{e}}$ & \multicolumn{1}{c}{$\mathrm{SN}^{\mathrm{f}}$} \\
\hline CCCMA & 8.53 & 0.18 & 8.70 & 0.39 & 8.65 & -0.16 \\
CNRM & 1.28 & 0.32 & 6.05 & 0.16 & 10.00 & 0.66 \\
CSIRO3.0 & 4.06 & 0.07 & 2.02 & -0.10 & 5.65 & -0.19 \\
GFDL2.0 & -1.06 & -0.10 & 2.34 & 0.49 & 13.16 & -0.20 \\
GISS & 2.79 & 0.39 & 3.07 & 0.40 & 24.66 & 3.26 \\
IPSL & 4.31 & 0.09 & 6.55 & 0.00 & -7.47 & -1.55 \\
MIUB & -2.85 & -0.16 & 0.61 & -0.07 & -7.93 & -1.36 \\
MPI & 5.70 & 0.54 & 6.35 & 0.48 & 8.09 & 0.09 \\
MRI & 3.32 & 0.09 & 0.75 & -0.03 & 3.56 & -0.54 \\
Ensemble & & & 3.10 & & & \\
Average & 2.68 & 0.16 & & 0.19 & 6.49 & 0.00 \\
\hline
\end{tabular}

${ }^{a}$ DA is downscaled changes of average monthly precipitation amounts with only relative humidity $(\mathrm{mm})$.

${ }^{\mathrm{b}} \mathrm{DN}$ is downscaled changes of average monthly number of rain days with only relative humidity (day).

${ }^{c} \mathrm{DAB}$ is downscaled changes of average monthly precipitation amounts $(\mathrm{mm})$ with both relative humidity and specific humidity $(\mathrm{mm})$.

${ }^{d}$ DNB is downscaled changes of average monthly number of rain days with both relative humidity and specific humidity $(\mathrm{mm})$.

e SA is simulated changes of average monthly precipitation amounts (mm)

${ }^{\mathrm{f}} \mathrm{SN}$ is simulated changes of average monthly number of rain days (day).

humidity variables (Fig. 4c), but the changes in that case are all positive and larger than those changes in the downscaled results without specific humidity. One possible explanation for this spatial pattern is suggested by Rowell and Jones (2006), who found that the large landsea contrast in lower-tropospheric warming will lead to reduced humidity in air advected from the Great Lakes to the continent and, therefore, reduced rainfall. For the raw GCM simulation (Fig. 4e), the gradient is from northeast to southwest, which is very different from the downscaled results. Note, however, that the figure implies more spatial information than actually exists for the raw GCM values. The $4^{\circ} \times 7^{\circ}$ area represents between 1 and $8 \mathrm{GCM}$ grid cells, depending on the original GCM resolution, with 6 of the models having only one or two grid cells over the region (Table S1, http://dx.doi.org/ 10.1175/JCLI-D-11-00565.s1.). This illustrates the danger of simply interpolating low-resolution GCM data to a higher-resolution spatial grid. The uncertainty that exists in applying GCM data at the local scale is considerably reduced by downscaling to a finer grid or to point locations.

For the changes in monthly rain day totals, the spatial patterns of the two downscaled results are similar to the patterns of precipitation amount changes (Figs. 4b,d). For the raw GCM simulations (Fig. 4f), nearly all the stations have a reduced number of monthly rain days. Increased precipitation with fewer rain days indicates an increase in precipitation intensity, a common feature of both observation and GCM simulations of future climate globally (Tebaldi et al. 2006; Ning and Qian 2009) and for the Northeast United States (Hayhoe et al. 2007; Shortle et al. 2009).

Figures $4 \mathrm{~g}-\mathrm{r}$ show projected changes in the various precipitation metrics for summer and winter. The GCMs show weak agreement with each other in summer and strong agreement in winter in projected precipitation over Pennsylvania (see, e.g., Fig. 11.12 in Christensen et al. 2007; Shortle et al. 2009). From Figs. 4g-1, we see that both downscaling approaches imply decreased average precipitation and reduced numbers of rain days over nearly all of Pennsylvania in summer. The raw GCM precipitation projections, by contrast, suggest increased monthly precipitation amounts and decreased monthly number of rainy days for most of Pennsylvania. For winter months (Figs. 4m-r), both downscaling approaches and the raw GCM simulations indicate increased average monthly precipitation amounts and rain day totals. The magnitudes of the downscaled changes, however, are once again smaller than the simulated changes. As discussed below, this observation may in part relate to the greater role played by changes in the $\mathrm{NAO}$ in the downscaled precipitation projections.

\section{3) ANNUAL VERSUS SEASONAL TRENDS}

An aggregate measure of the projected twenty-firstcentury trends in precipitation is provided by averaging the differences between middle twenty-first century 2046-65 and late twentieth century (1981-2000) across either all 17 stations, all nine GCM simulations, or across both stations and GCM simulations. Figure 5 shows the changes in monthly precipitation amount ( $y$ axis) versus changes in monthly rain day totals ( $x$ axis) for the whole year (Figs. 5a,b), summer (Figs. 5c,d), and winter (Figs. $5 e, f)$, defined as the differences between the period 204665 and the period 1981-2000. Figures 5a,c,e show the results for nine GCMs averaged over 17 stations, and Figs. $5 b$,d,f show the results for 17 stations averaged over nine GCMs.

Considering all days of the year, downscaling of the model simulations yields predictions of increased monthly mean precipitation for both downscaling approaches and all nine raw GCM simulations (Fig. 5a). Increases in monthly mean precipitation are observed for all 17 stations using either the raw model precipitation or the dual-humidity variables downscaling scheme and for most stations using the relative humidity-only downscaling scheme (Fig. 5b). 
Annual
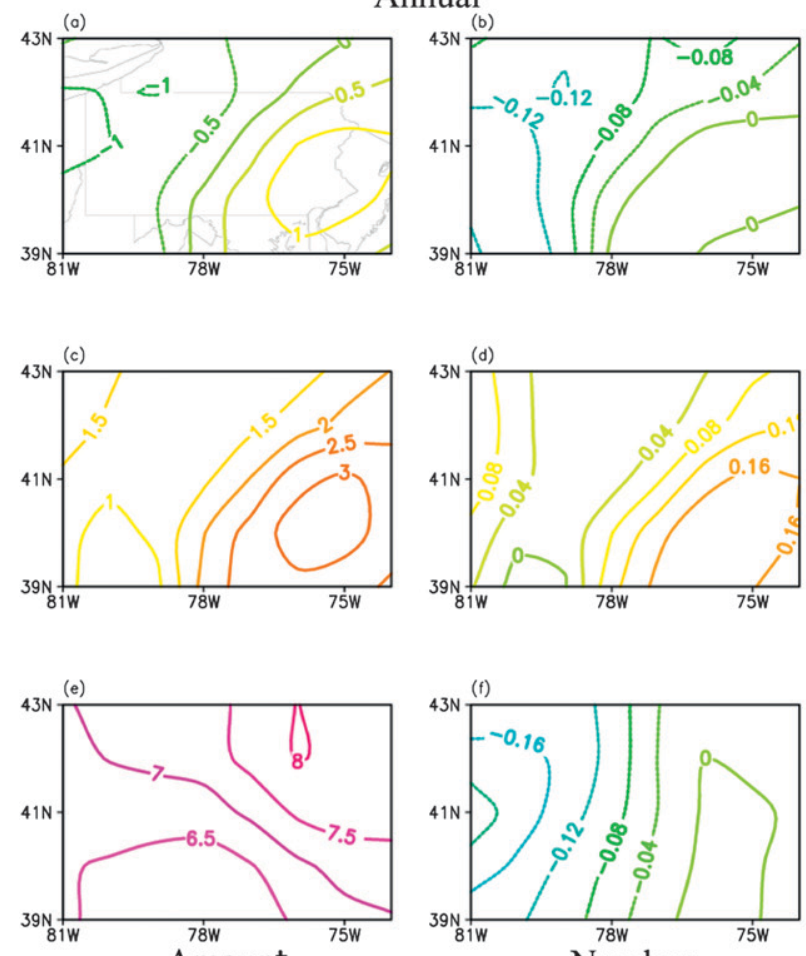

Amount
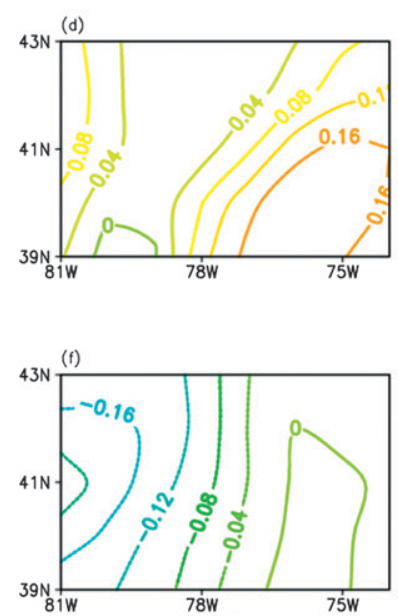

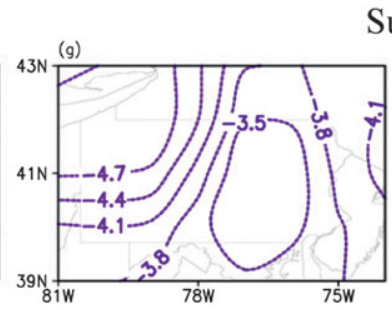

Summer
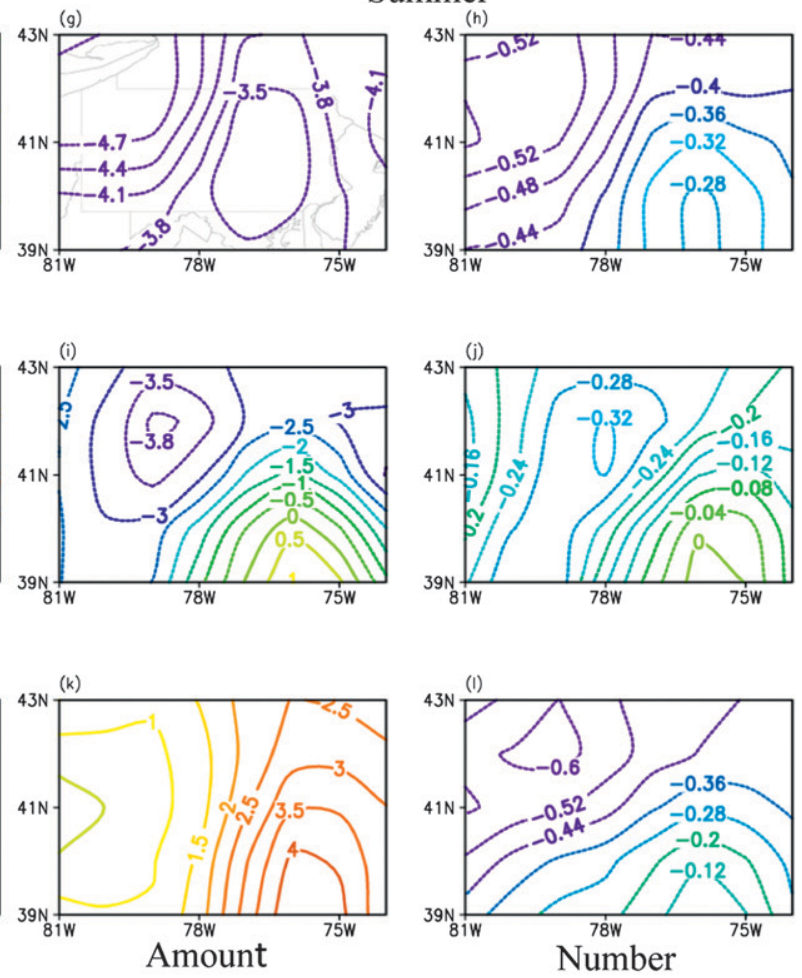

Winter
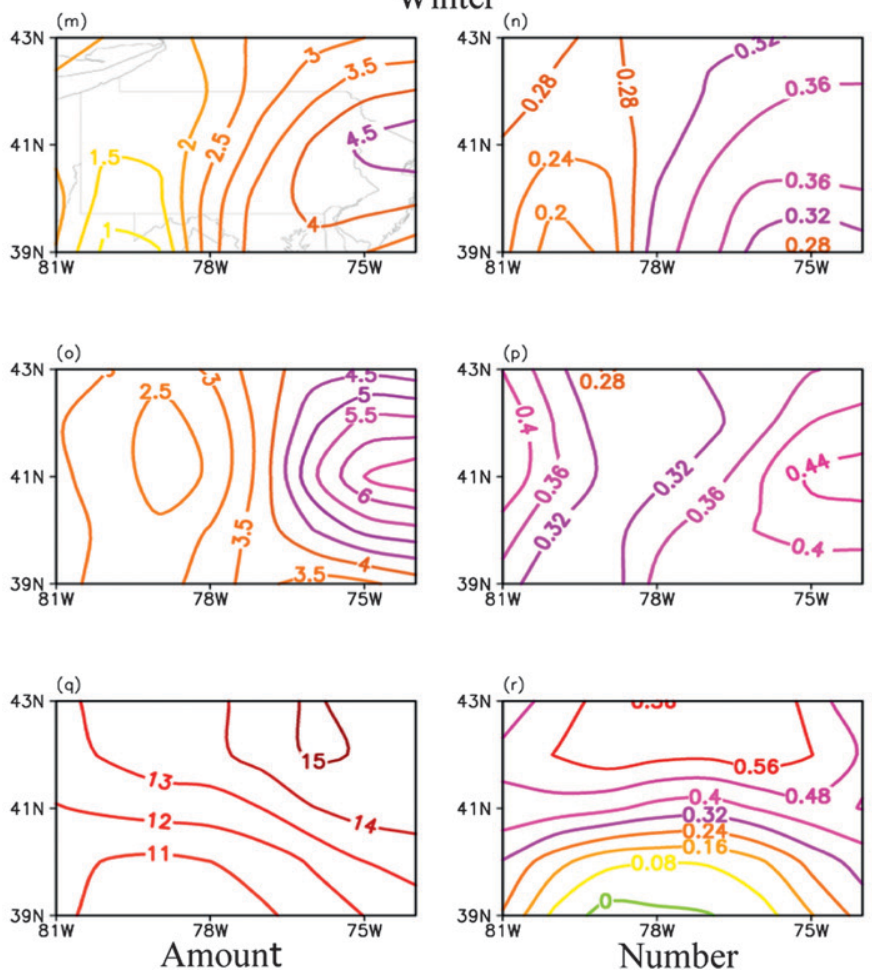

FIG. 4. The spatial distributions of changes in (a)-(f) annual, (g)-(f) summer, and (m)-(r) winter (left) mean monthly precipitation totals (in $\mathrm{mm}$ ) and (right) number of rain days (in days) based on (top) downscaling using relative humidity, (middle) downscaling using relative humidity and specific humidity, and (bottom) raw GCM precipitation. 

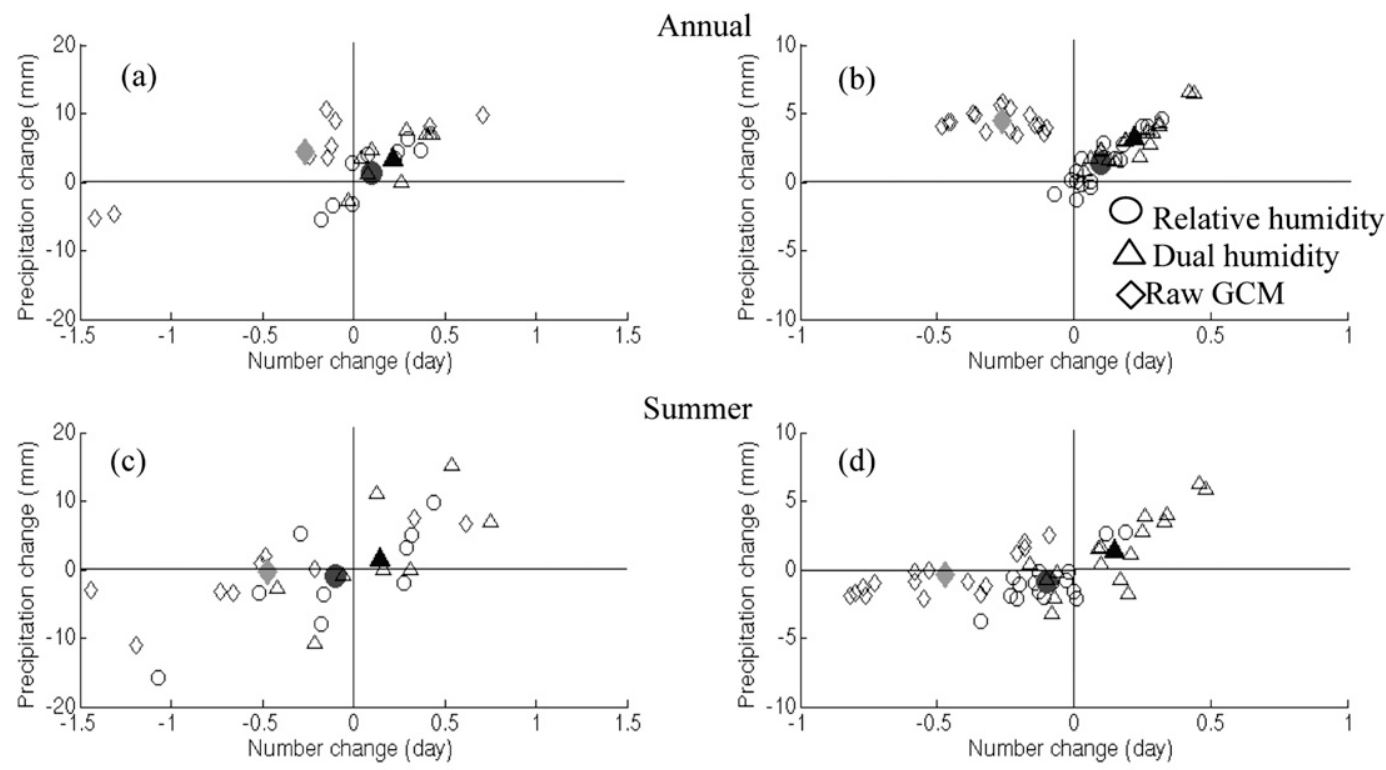

Summer
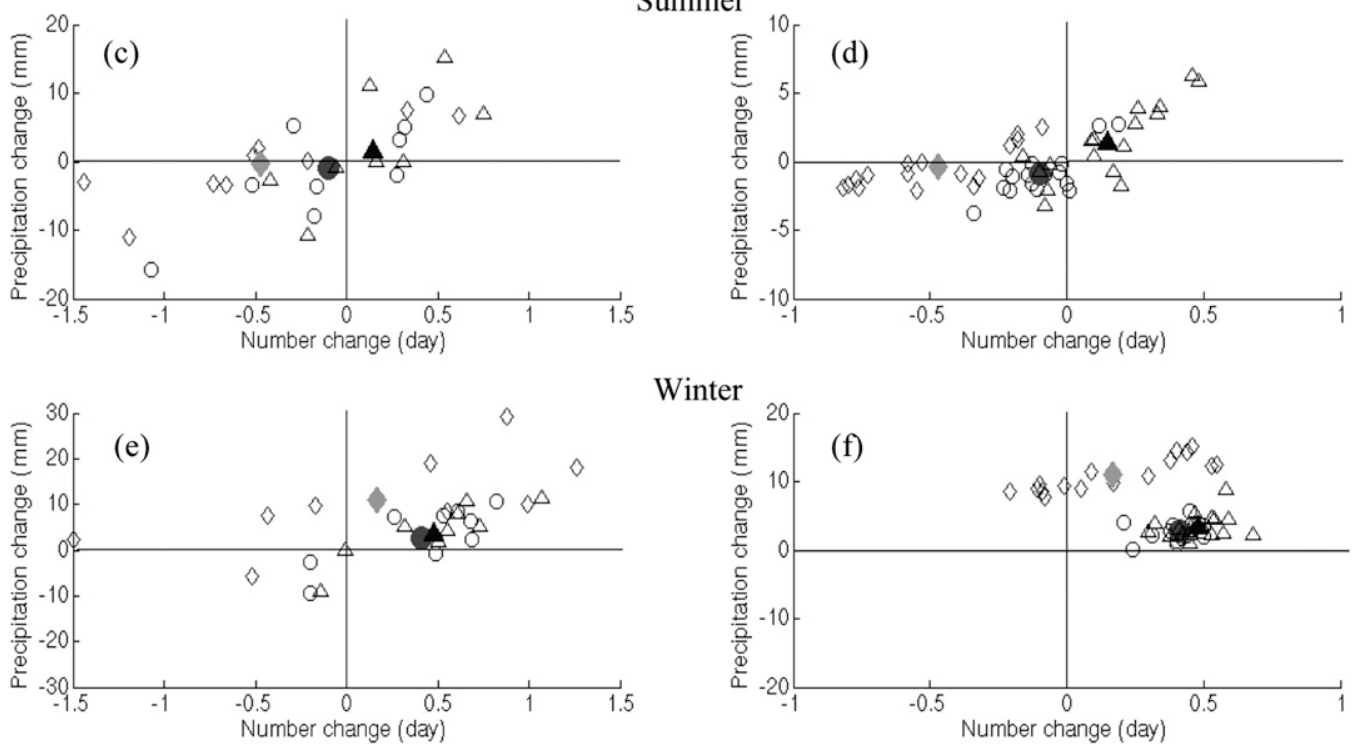

Winter

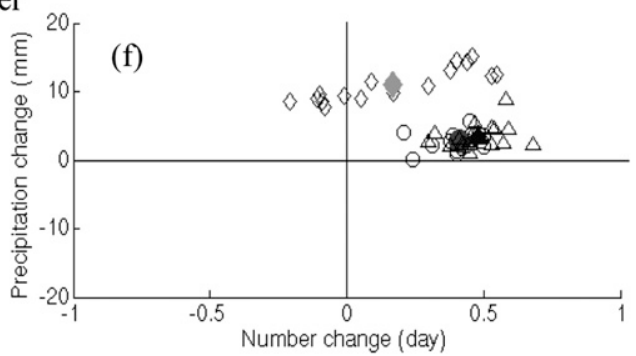

FIG. 5. Future change of average monthly precipitation amount ( $y$ axis, unit: $\mathrm{mm}$ ) and monthly number of rain days ( $x$ axis, Unit: day) for (a),(b) annual, (c),(d) summer, and (e),(f) winter months averaged over (a),(c),(e) all 17 stations and (b),(d),(f) over nine GCMs for the downscaled results with only relative humidity (circles), downscaled results from both relative and specific humidities (triangles), and raw GCM-simulated precipitation (diamonds) between period 2046-65 and period 1981-2000. The larger solid symbols show the average values of the group.

For rain day totals, Fig. 5a shows that most GCM simulations (averaging over stations) predict increasing trends using either downscaling approach. By contrast, the raw simulated precipitation indicates decreasing trends for most of the simulations. All stations exhibit increases using the dual humidity downscaling scheme (Fig. 5b). The stations cluster around zero with one station showing a decreasing trend in the downscaling with only relative humidity. The raw GCM precipitation fields, by contrast, show decreasing trends for all stations.

Greater inconsistencies are found at the seasonal scale. For the summer season, averaging across stations (Fig. $5 c$ ), roughly half of the GCM simulations predict increasing trends in both monthly mean precipitation and rain day totals for both downscaling schemes as well for the raw model precipitation field. Nearly all the GCMs predicting increases in monthly mean precipitation also predict increases in rain day totals. Averaging across GCM simulations (Fig. 5d), most stations in the relative humidity-only downscaling scheme, as with the raw GCM precipitation field, show decreasing trends for both monthly mean precipitation and rain day totals. Using the dual humidity variables downscaling, however, most stations show increasing trends for both monthly precipitation amounts and monthly rain day totals.

For the trends of winter months, when averaging across nine GCMs (Fig. 5e), most stations show consistent increasing trends on both monthly precipitation amounts and monthly number of rain days. This is more evident in the results averaged across 17 stations (Fig. 5f), with nearly all the GCM simulations showing increasing trends on both monthly precipitation amounts and monthly number of rain days, except several stations in the raw GCM simulations. Usually, the trends from both downscaling approaches are smaller than the trends from the raw GCM simulations.

Figure 6 compares the histograms of monthly precipitation amounts and monthly rain day totals based on an 

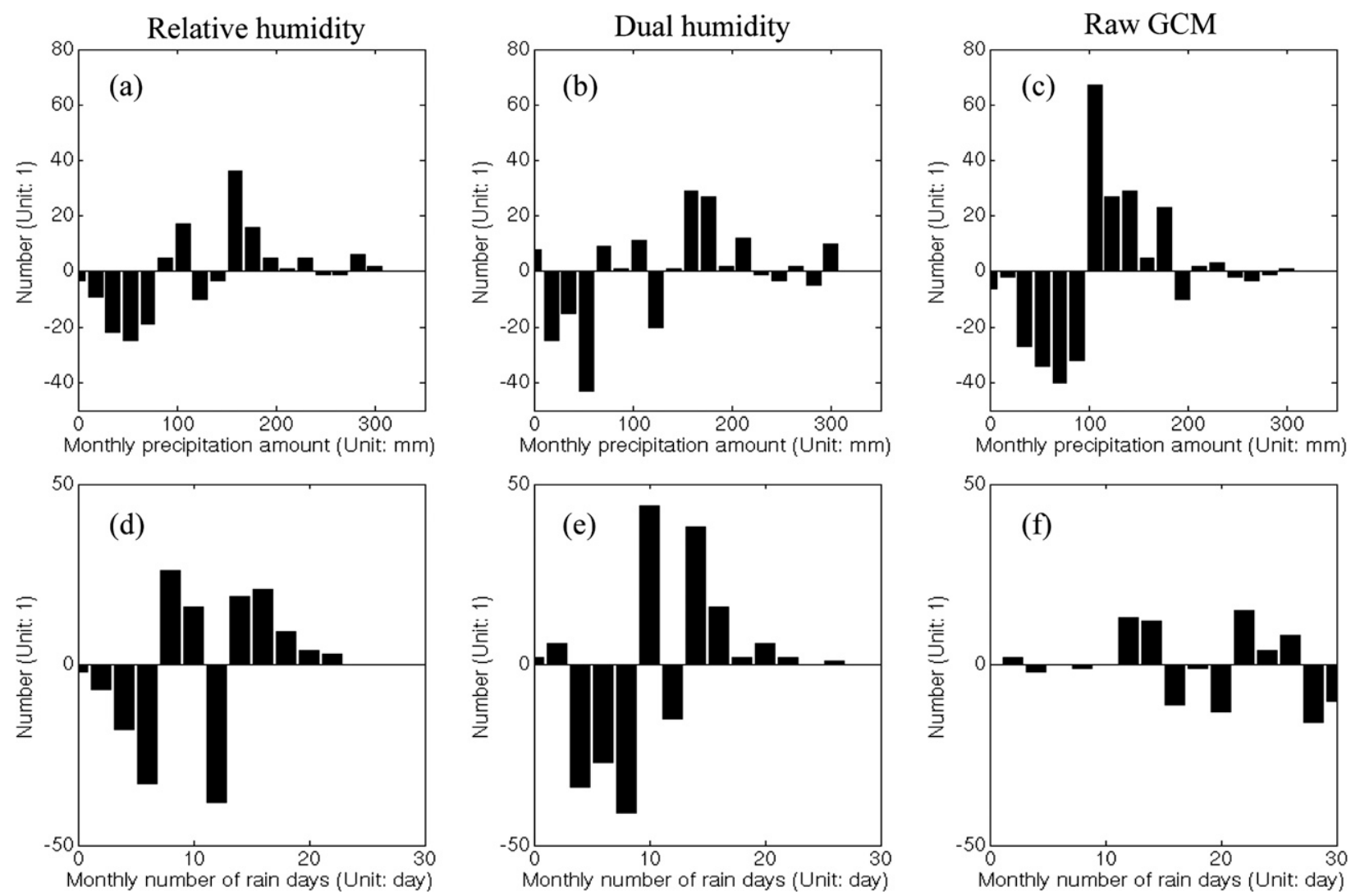

FIG. 6. The changes of histogram of the (a)-(c) monthly precipitation amounts and (d)-(f) monthly number of rain days between future period 2046-65 and historical period 1981-2000 from the (a),(d) downscaled results with only relative humidity, (b),(e) downscaled results with both humidity variables, and (c),(f) raw GCM simulations.

ensemble of all nine GCMs from three approaches for a single station, Harrisburg. For both sets of downscaling results and for the raw GCM projections, there is a shift to the right with a fewer number of occurrences of months with lower rainfall amounts and an increase in months with higher rainfall totals (Figs. 6a-c). For the two downscaling approaches (Figs. $6 \mathrm{~d}, \mathrm{e}$ ), there is also a shift with a fewer number of occurrences of months with small number of rainy days and an increase in months with larger number of rainy days. For the raw GCM projections (Fig. 6f), this shift appears on the month with number of rainy days larger than 10 , and the magnitude of the shift is much smaller suggesting a shift toward more intense rainfall events.

\section{c. Analysis of uncertainties}

\section{1) COMPARISONS OF INTER-GCM UNCERTAINTIES}

There is considerably more uncertainty in the GCM simulations of precipitation than there is in their ability to simulate the larger-scale characteristics of the atmospheric state. Because we use these large-scale characteristics to downscale the precipitation, we get much closer agreement between the GCMs with the downscaled data than we do between the raw GCM simulations of precipitation. Consequently, the downscaling reduces some of the uncertainty that derives from different GCM parameterization schemes. The uncertainty introduced by using different input parameters for the downscaling is much less than the reduction in uncertainty obtained by using either of the downscaled datasets compared to the raw GCM values. This is further illustrated in Fig. 7, comparing the downscaled and simulated ensemble-weighted averages of mean monthly precipitation amount and monthly number of rain days averaged across all 17 stations, together with the corresponding inter-GCM uncertainties (computed as the root-mean-square difference from the ensemble average).

Figure 7 a compares the downscaled and simulated ensemble-weighted averages and inter-GCM uncertainties of mean monthly precipitation amount. For the annual changes using the downscaled results with only 
(a)

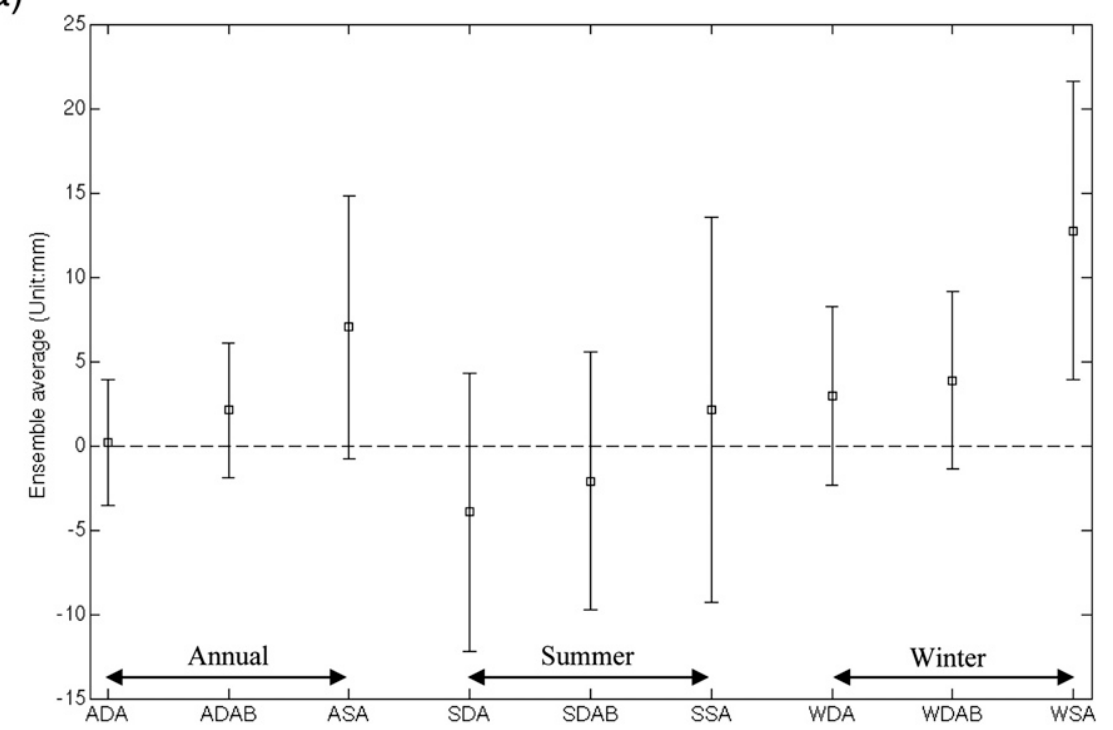

(b)

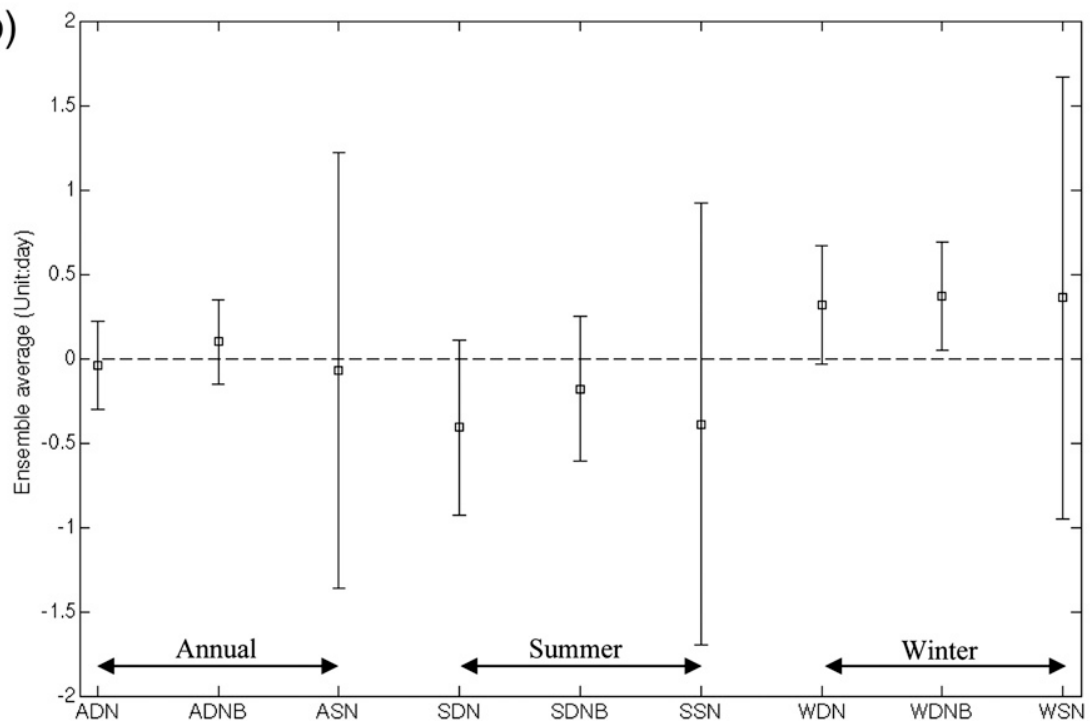

FIG. 7. The ensemble averages of (a) monthly precipitation amount changes and (b) monthly number of rain days changes across nine GCMs (squares) and the corresponding inter-GCM uncertainties (whiskers) for annual, summer, and winter months. The acronyms used in this figure as defined as follows: downscaled amount changes with only relative humidity for annual months (mm) (ADA); downscaled amount changes with dual humidity variables for annual months (mm) (ADAB); amount changes from raw GCM simulations for annual months ( $\mathrm{mm}$ ) (ASA); downscaled amount changes with only relative humidity for summer months (mm) (SDA); downscaled amount changes with dual humidity variables for summer months (mm) (SDAB); amount changes from raw GCM simulations for summer months (mm) (SSA); downscaled amount changes with only relative humidity for winter months (mm) (WDA); downscaled amount changes with dual-humidity variables for winter months (mm) (WDAB); amount changes from raw GCM simulations for winter months (mm) (WSA); downscaled number changes with only relative humidity for annual months (day) (ADN); downscaled number changes with dual-humidity variables for annual months (day) (ADNB); number changes from raw GCM simulations for annual months (day) (ASN); downscaled number changes with only relative humidity for summer months (day) (SDN); downscaled number changes with dual-humidity variables for summer months (day) (SDNB); number changes from raw GCM simulations for summer months (day) (SSN); downscaled number changes with only relative humidity for winter months (day) (WDN); downscaled number changes with dual-humidity variables for winter months (day) (WDNB); and number changes from raw GCM simulations for winter months (day) (WSN). 
relative humidity, five GCMs predict increases for the monthly precipitation (see Table $\mathrm{S} 2$ for details; available online at http://dx.doi.org/10.1175/JCLI-D-11-00565.s1.), and the ensemble average of the nine GCMs is $0.18 \mathrm{~mm}$. For the downscaled results with both humidity values, six of nine GCMs predict increased monthly precipitation, and the ensemble-weighted average is $2.09 \mathrm{~mm}$. For the raw GCMs simulations, seven of nine GCMs predict increases for the monthly precipitation, with an average of $7.02 \mathrm{~mm}$. In each case, the root-mean-square difference from the ensemble weighted average is the greatest for the raw GCM precipitation.

Moreover, we also see that there is a seasonal difference, with the summer season showing greater variability between models than winter. For summer precipitation, although five of the GCMs simulate decreases in average monthly precipitation amounts, the ensemble-weighted average shows a $2.15 \mathrm{~mm}$ increase. This is primarily a result of the large increase of $31.75 \mathrm{~mm} \mathrm{(40 \% )} \mathrm{in} \mathrm{the} \mathrm{GISS}$ GCM. Note that this model did less well at simulating the historical precipitation with a $-45 \%$ error compared to observations (Ning et al. 2012). The downscaling with one and two humidity values result in six and four models producing drying respectively. In both cases, the models are showing either a small increase in precipitation or a larger decrease, such that the weighted ensemble average suggests a slight drying. Including the specific humidity as a parameter to help define the atmospheric state increases the number of GCMs that project precipitation increases when averaged across the state, but the ensemble mean is still negative. This suggests that there is still considerable uncertainty in the summer precipitation projections, although the most likely projection is for little change or possibly a slight drying. This uncertainty in summer precipitation projections and the large difference between the GCM and downscaled projections also exist in dynamical downscaling conducted for North America (Chen et al. 2003; Han and Roads 2004).

During winter, eight of the nine raw GCM projections give increased monthly precipitation. Seven GCMs project increases for the downscaling with $\mathrm{RH}$ only, and six for the downscaling with both humidity values. This level of agreement is most likely because of the strong synoptic control on precipitation during the winter months, with the differences between the raw GCM values and the downscaling arising because of the inability of the GCMs to capture the higher resolution spatial variability. For both summer and winter, the root-mean-squared error is again much smaller for the downscaled projections than for the raw GCM data.

Figure $7 \mathrm{~b}$ shows similar results but for the monthly number of rain days changes. For annual changes, both the downscaling with only relative humidity and raw
GCM simulation predict decreases of -0.04 and -0.07 days, while the downscaling with dual humidity variables predicts an increase of 0.1 days. The downscaled interGCM uncertainty with only relative humidity is 0.26 days, and the downscaled uncertainty with dual-humidity variables is 0.25 days. And both of them are smaller than the uncertainty from raw GCM simulations 1.29 days.

For summer months, both downscaling approaches and raw GCM simulations predict negative ensemble averages. The downscaling approaches with only relative humidity and with dual humidity variables predict the ensemble averages of -0.41 days and -0.18 days, and the raw GCM simulations predict the ensemble average -0.39 days. The inter-GCM uncertainties of the downscaled results are 0.52 and 0.43 days, which are both smaller than the uncertainty of the raw GCM simulations (1.31 days). Based on our downscaling results and GCM simulated results over the mid-Atlantic region, it seems that the increased humidity brought by global warming does not mean more or stronger convection in the future.

For winter months, both downscaling approaches show consistency with the GCM simulations on the ensemble average but with reduced inter-GCM uncertainty. The ensemble averages of the two downscaling approaches are 0.32 days and 0.37 days, which are close to the raw GCM simulation (0.36 days). The inter-GCM uncertainties of the downscaled results are 0.35 and 0.32 days, which are still smaller than the uncertainty of raw GCMs simulations (1.31 days).

So it can be concluded that for projections of both precipitation amount and number of rain days, the two downscaling approaches can obviously reduce the interGCM uncertainties introduced by different physical parameterizations from different GCMs.

\section{2) NAO INFLUENCE ON WINTER PRECIPITATION}

\section{(i) Modern observational relationships}

To examine the control of large-scale climate dynamics on the synoptic circulation patterns governing winter precipitation variability, we examined the relationship between the primary such dynamical feature-the North Atlantic Oscillation (NAO) - and winter precipitation variability over Pennsylvania that is the focus of our study. Figure 8 a shows the time series of the observed winter [December-March (DJFM)] NAO index, taken from the University of East Anglia (Jones et al. 1997; supplemented by more recent values available at http:// www.cru.uea.ac.uk/ timo/datapages/naoi.htm). Substantial variability is seen on both interannual and interdecadal time scales. High-NAO (defined as anomalies greater than +1 standard deviation above the long-term 

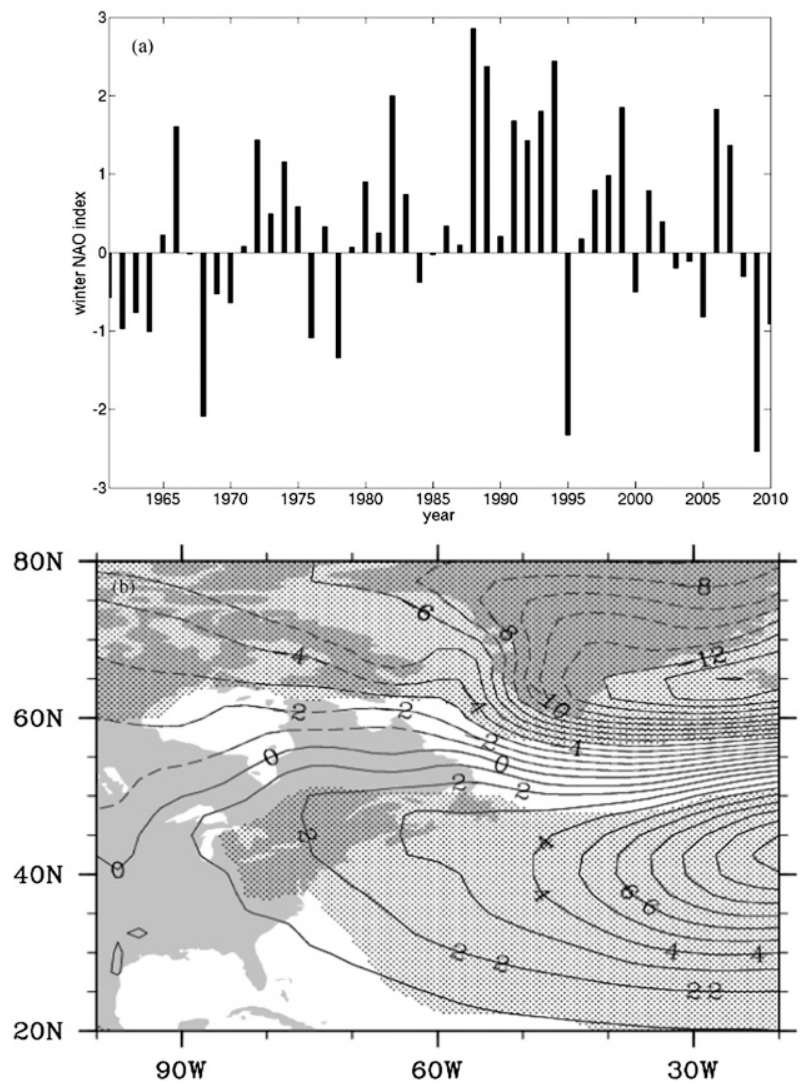

FIG. 8. The time series of the standard winter (DJFM) NAO index for period (a) winter 1961/62-2010/11 and (b) the SLP differences between the winters with high- and low-NAO indices (unit: hPa). The shading indicates differences significant at the $p=$ 0.05 level.

mean) years are 1966/67, 1982/83, 1988/89, 1991/92, 1992/ 93, 1993/94, 1994/95, 1999/2000, while low-NAO years (defined as anomalies as exceeding -1 standard deviation below the long-term mean) are 1962/63, 1964/65, 1968/69, 1976/77, 1978/79, 1995/96, and 2000/01.

We performed a series of analyses to confirm the NAO influence on synoptic-scale winter precipitation in Pennsylvania. In Table 2, we composite winter precipitation (December-March) for the years with high- and low-NAO indices. All stations except West Chester (this exception is likely due to the large amounts of missing data for this station in question) show a clear NAO influence, with greater mean precipitation during lowNAO years and less precipitation during high-NAO years. The average differences over the 17 stations are significant at greater than the $p=0.05$ level using Student's $t$ test, consistent with the previously established finding that positive NAO winters are associated with reduced midlatitude storm influences on the region (Dong et al. 2010). In Fig. 8b, we show the composite SLP difference between the high- and low-NAO winters, which displays an increased penetration of the mean subtropical Bermuda/Azores high into the mid-Atlantic region of the United States, implying a blocking of midlatitude storms, conducive to reduced storm-related winter precipitation in the region.

The relationship between the NAO and synopticscale precipitation was then evaluated for each of the nine GCM simulations. For each simulation, a winter NAO series was calculated as the difference between simulated SLP over the grid points closest to the centers of Bermuda/Azores high and Greenland low. To assess the ability of the models to reproduce the observed influence of the NAO on the synoptic-scale atmospheric circulation, we calculated the difference in SOM node frequencies between high- and low-NAO winters for each GCM simulation over the historical period and compared with a parallel analysis based on the NCEP reanalysis data (Fig. 9). We also evaluated the statistical significance of the node frequency difference patterns (Fig. S2, http://dx.doi.org/10.1175/JCLI-D-11-00565.s1).

Having found that the main features in the SOM difference patterns shown in Fig. 9 are statistically significant (Fig. S2, http://dx.doi.org/10.1175/JCLI-D-11-00565.s1), we evaluated the degree of similarity between the observed (NCEP) and GCM-simulated difference patterns. We calculated the pattern correlation between the NCEP SOM difference pattern and that of each of the 9 GCM simulations, employing a one-sided hypothesis test (since only a positive correlation is physical) assuming $N=99-$ $2=97$ degrees of freedom. Only two of the models (GISS and CCCMA) provide a statistically significant $(p<0.05)$ match with the observational SOM difference pattern, suggesting that these two models are best able to reproduce the observed influence of the NAO on the distribution of synoptic atmospheric circulation states (see Fig. 9; the one-sided $p=0.05$ significance threshold is $r=0.166$ ). Most of the models do, however, at least capture the general shift from the upper-left corner of the SOM (associated with high sea level pressure) to the bottom-left corner (associated with low sea level pressure).

There are some caveats to keep in mind in this analysis. In the NCEP observations, there is some tendency for neighboring SOM nodes to change in opposite directions, suggesting that the NAO influence on synoptic circulation states is fairly subtle, that is, that the differences between high and low positive NAO states results in somewhat subtle shifts in the strength or location of high and low pressure centers. With the models on the other hand, the changes in SOM occupancy show greater coherency in state space, with adjacent SOM nodes tending to change in the same direction. This discrepancy might indicate a too simplified representation of synoptic 
TABLE 2. The average monthly precipitation amounts of the high- and low-NAO winters and their difference (unit: mm).

\begin{tabular}{|c|c|c|c|c|}
\hline $\begin{array}{c}\text { Station } \\
\text { No. }\end{array}$ & Station names & $\begin{array}{c}\text { Average monthly precipitation } \\
\text { of the winters with NAO indices } \\
\text { larger than one standard deviation } \\
\text { to the mean }\end{array}$ & $\begin{array}{c}\text { Average monthly precipitation } \\
\text { of the winters with NAO indices } \\
\text { smaller than one standard deviation } \\
\text { to the mean }\end{array}$ & $\begin{array}{l}\text { Difference between the } \\
\text { average monthly precipitation } \\
\text { of high- and low-NAO winters }\end{array}$ \\
\hline 1 & Allentown & 101.76 & 117.11 & -15.34 \\
\hline 2 & Chambersburg & 87.37 & 99.61 & -12.25 \\
\hline 3 & Franklin & 96.03 & 103.69 & -7.66 \\
\hline 4 & Greenville & 76.60 & 92.59 & -15.99 \\
\hline 5 & Harrisburg & 85.40 & 99.01 & -13.61 \\
\hline 6 & Johnstown & 108.51 & 134.48 & -25.96 \\
\hline 7 & Montrose & 115.96 & 130.71 & -14.75 \\
\hline 8 & New Castle & 67.46 & 87.75 & -20.29 \\
\hline 9 & Palmerton & 63.90 & 95.94 & -32.04 \\
\hline 10 & Ridgway & 89.75 & 110.06 & -20.31 \\
\hline 11 & State College & 89.16 & 97.88 & -8.71 \\
\hline 12 & Stroudsburg & 100.44 & 125.91 & -25.47 \\
\hline 13 & Towanda & 69.59 & 77.10 & -7.52 \\
\hline 14 & Uniontown & 94.90 & 101.25 & -6.35 \\
\hline 15 & Warren & 100.42 & 111.39 & -10.97 \\
\hline 16 & West Chester & 102.50 & 94.84 & 7.66 \\
\hline \multirow[t]{2}{*}{17} & York & 99.67 & 100.33 & -0.66 \\
\hline & Average & 91.14 & 104.69 & -13.54 \\
\hline
\end{tabular}

circulation states in the models, though it could alternatively result from biases in observational (NCEP reanalysis and station precipitation) data.

\section{(ii) Projected changes}

Figure 10 shows the relationship between projected twenty-first-century trends of the NAO and projected changes in mean winter (DJFM) Pennsylvania precipitation. The NAO trends were defined by the best-fit linear trend in the diagnosed NAO series for each GCM over the common twenty-first-century period 2004-99. The trends in precipitation were defined, as earlier, by the differences between the simulated future period 2046-65 and the simulated late twentieth-century period 1981-2000 as before, averaged over all 17 Pennsylvania stations. The symbols for GISS and CCCMA are highlighted for reasons discussed in the previous section.

From the figure, we can see that there is a very strong relationship between changes in the NAO and changes in winter precipitation, consistent with the substantial dynamical control on Pennsylvania winter precipitation evident for the late twentieth century in both NCEP observations and the GCMs (see previous section). Those models with the greatest tendency toward the positive phase of the winter NAO tend to show the greatest projected reduction in winter precipitation. The relationship is substantially stronger for the downscaled precipitation than for the raw GCM precipitation: $r=$ -0.74 and $r=-0.72$ for the relative humidity-only and dual-humidity downscaling. respectively $(p \approx 0.01$ in both cases), versus a much lower $r=-0.22(p=0.28)$ for the raw GCM-simulated winter precipitation. It thus appears that large-scale climate dynamics related to $\mathrm{NAO}$ are playing a far more important role in winter precipitation trends in the downscaled precipitation products than in the raw GCM simulations themselves. It is reasonable to speculate that this is due to limitations in the raw GCM simulation itself in capturing the subtle controls on winter synoptic-scale precipitation in the region that are alleviated or at least reduced through the use of appropriate downscaling methods. This can be tested through the composite analysis of the downscaled precipitation and raw GCM simulated precipitation during the GCM simulated high- and low-NAO winters in the future study.

Given the critical apparent relationship in the downscaling exercises between projected changes in the winter NAO and Pennsylvania winter precipitation, it is clear that clarifying and understanding the nature of response of the NAO to anthropogenic forcing is critical to reducing uncertainty in projections of winter precipitation. We note that six of the nine GCMs predict a tendency toward the positive phase of the NAO in response to projected anthropogenic forcing. That response is due at least in part to the intensification and westward expansion of the North Atlantic boreal winter subtropical High with increasing $\mathrm{CO}_{2}$ ( $\mathrm{Li}$ et al. 2011), though more subtle responses involving the stratospheric response to anthropogenic forcing may be important (Miller et al. 2006).

Notably, the GISS model, which as discussed above displays the closest relationship with the observations with regard to the influence of the winter NAO on 

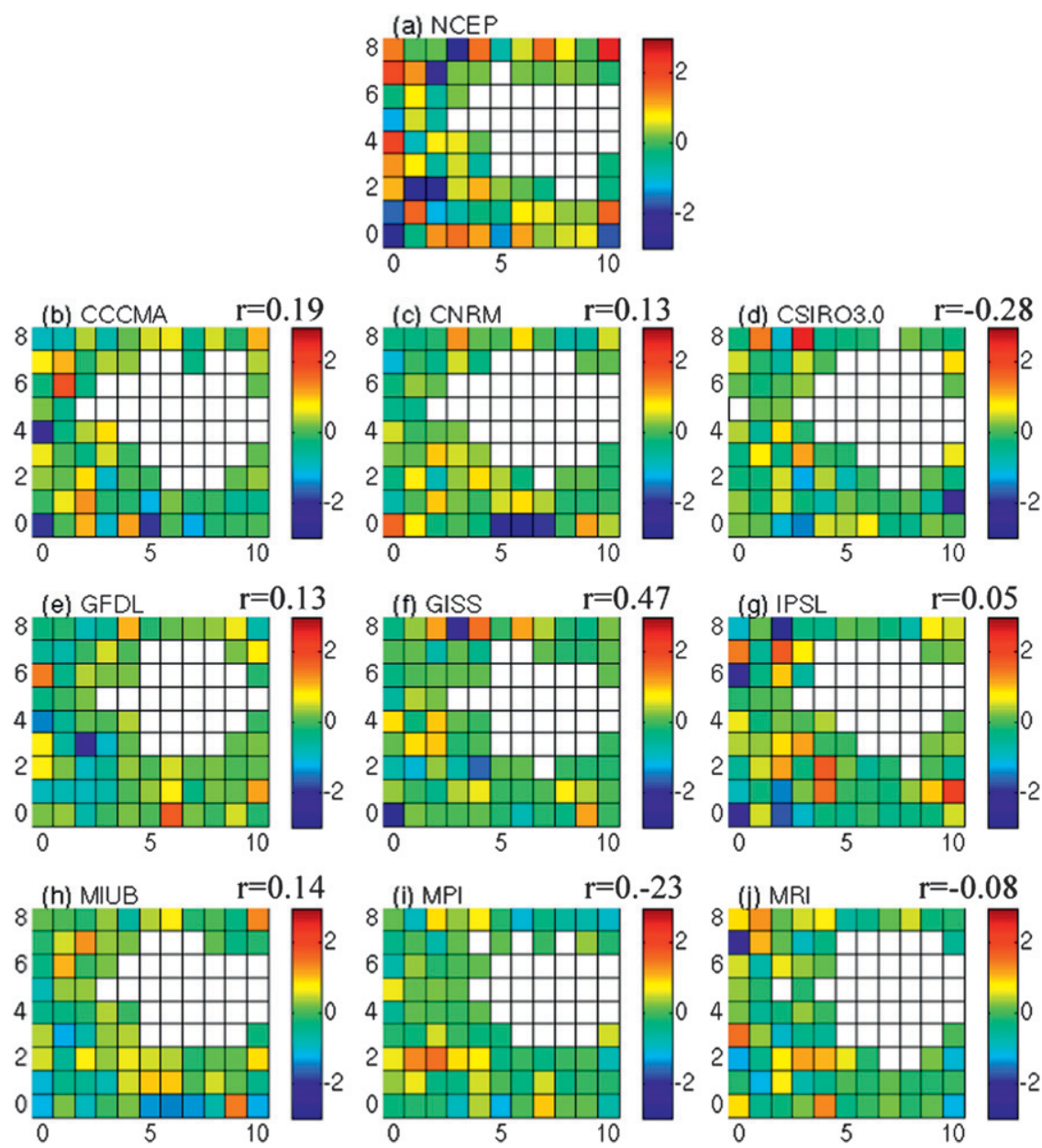

FIG. 9. The difference of the frequency distributions of winters with high- and low-NAO indices from NCEP data and nine GCMs (unit: \%). Spatial correlations with NCEP pattern are given for each of the nine GCMs. White squares represent values of zero.

synoptic-scale circulation states influencing winter precipitation, projects a (modestly) negative NAO response to twenty-first-century anthropogenic forcing. This response contributes to a larger projected increase in winter precipitation. On the other hand, the other model (CCCMA) that reproduces reasonably well the observed NAO influence on synoptic-scale circulation, displays an opposite trend toward a more positive $\mathrm{NAO}$, mitigating any tendency for increased winter precipitation.

As noted earlier, a weaker relationship is found between the projected changes in the winter NAO and winter precipitation using the raw GCM precipitation field (Fig. 10c). We speculate that synoptic-scale atmospheric dynamics are playing an artificially weak role in this case, owing to a combination of low model resolution and imperfect physical parameterizations of the processes governing winter-season synoptic-scale precipitation. In the absence of a realistic representation of large-scale dynamical controls on winter precipitation, the models are presumably producing an increase in precipitation in association with the larger atmospheric water vapor mixing ratios in a warmer winter climate. Consequently, the models' raw precipitation field, in eight of the nine model simulations, shows an increase in winter precipitation in the region.

\section{Conclusions}

Using a statistical downscaling method based on SOMs, we have presented projections of future (midtwenty-first century) changes in precipitation over the state of Pennsylvania. To examine the sensitivity of future precipitation due to changes in atmospheric water vapor associated with global warming, we tested two alternative approaches to downscaling, using either one (relative humidity) or two 

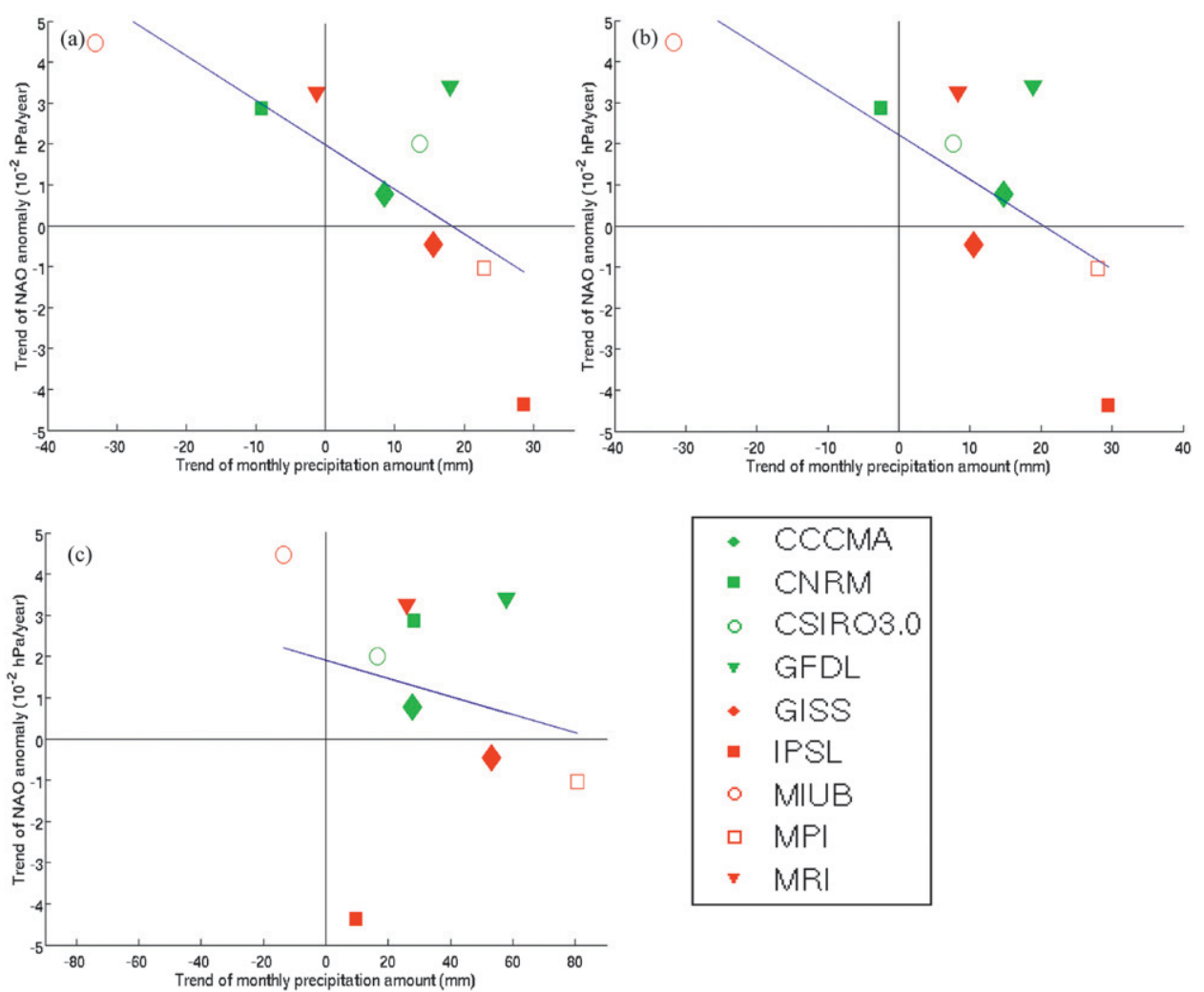

FIG. 10. Projected trend in NAO ( $y$ axis, unit: $10^{-2} \mathrm{hPa} \mathrm{yr}^{-1}$ ) against projected trend in mean winter precipitation over Pennsylvania ( $x$ axis, unit: $\mathrm{mm}$ ) with best-fit linear relationship (solid line). Shown are results based on (a) downscaling with only relative humidity $(r=-0.74, p=0.011)$, (b) downscaling with dual-humidity variables $(r=-0.72, p=0.014)$, and (c) the raw GCM-simulated winter precipitation $(r=-0.22, p=0.28)$. Results for GISS and CCCMA are highlighted as larger symbols, as discussed in text.

(relative and specific humidity) humidity variables in calibrating relationships between atmospheric variability and precipitation. An examination of the resulting SOM node distributions and the associated quantization errors suggests that the downscaling procedure is able to capture the prevailing synoptic circulation patterns that characterize the warmer climate of the midtwenty-first century for both cases, thus providing justification for using the SOMbased downscaling technique to project future changes in precipitation.

The downscaled as well as the raw GCM-simulated precipitation suggest an overall tendency for increasing trends in annual precipitation. Seasonal precipitation trends are more variable though. For summer precipitation, there is a large spread among models, and while the raw GCM precipitation and downscaling using relative humidity alone yield decreasing summer precipitation for most GCMs, downscaling using dual humidity variables yields increases. Indeed, the additional use of specific humidity in the downscaling always yields larger positive precipitation projections, suggesting that explicit use, in the training of the SOM, of specific humidity-which increases sharply with temperature via the ClaussiusClapeyron equation-yields greater sensitivity to the increased water vapor content of the atmosphere in a warming atmosphere.

For winter precipitation, there is greater agreement among GCMs and downscaling approaches and with raw GCM precipitation with regard to the projected tendency for an increase in precipitation, but the magnitude is strongly dependent on atmospheric dynamics related to the NAO. Particularly in the downscaled estimates, which explicitly incorporate synoptic-scale atmospheric dynamics in estimating precipitation, there is a tendency for greater winter precipitation increases in those models with less positive-trending changes in the NAO. In fact, downscaling of the minority of models that project a more negative NAO yields, in several cases, predictions of a decrease, rather than increase, in winter precipitation. 
A method for generating ensemble average downscaled precipitation estimates, based on the use of information from the quantization errors in the downscaling approach, is also introduced in this study. Application of this approach does reduce the inter-GCM uncertainty seen in projections based on the raw GCM precipitation field, and will in principle allow for reduced uncertainty in probabilistic projections of future precipitation changes. In our future work we will link this approach for creating downscaled ensemble projections to establish a novel Bayesian hydroclimatological framework able to produce probabilistic projections of hydrological indicators (Singh et al. 2011).

Acknowledgments. This research was supported by the Office of Science (BER), U.S. Department of Energy, Grant DE-FG02-08ER64641. Bruce Hewitson (University of Cape Town) kindly provided the downscaling code used, and Lisa Coop (University of Cape Town) provided assistance with the downscaling implementation. The NCEP grid data and station daily precipitation data over Pennsylvania were obtained from The National Centers for Environmental Prediction (NCEP) and the DOE's Carbon Dioxide Information Analysis Center (CDIAC) at Oak Ridge National Laboratory, respectively. The WCRP CMIP3 multimodel GCM dataset is made available by the Program for Climate Model Diagnosis and Intercomparison (PCMDI) and the WCRP's Working Group on Coupled Modeling (WGCM). Support of this dataset is provided by the DOE Office of Science. And the NAO data are kindly provided by the Climatic Research Unit from the University of East Anglia.

\section{REFERENCES}

Barnston, A. G., and R. E. Livezey, 1987: Classification, seasonality, and persistence of low-frequency atmospheric circulation patterns. Mon. Wea. Rev., 115, 1083-1126.

Barron, E. J., 2009: Beyond climate science. Science, 326, 643, doi:10.1126/science.1179807.

Benestad, R. E., 2002a: Empirically downscaled temperature scenarios for northern Europe based on a multi-model ensemble. Climate Res., 21, 105-125.

_ 2002b: Empirically downscaled multimodel ensemble temperature and precipitation scenarios for Norway. J. Climate, 15, 3008-3027.

_ 2004: Tentative probabilistic temperature scenarios for northern Europe. Tellus, 56A, 89-101.

Brekke, L., M. Dettinger, E. Maurer, and M. Anderson, 2008: Significance of model credibility in estimating climate projection distributions for regional hydroclimatological risk assessments. Climatic Change, 89, 371-394.

Chen, M. D., D. Pollard, and E. J. Barron, 2003: Comparison of future climate change over North America simulated by two regional models. J. Geophys. Res., 108, 4348, doi:10.1029/ 2002JD002738.
Christensen, J. H., and Coauthors, 2007: Regional climate projections. Climate Change 2007: The Physical Science Basis, S. Solomon et al., Eds., Cambridge University Press, 847-940.

Crane, R. G., and B. C. Hewitson, 2003: Clustering and upscaling of station precipitation records to regional patterns using selforginizing maps (SOMs). Climate Res., 25, 95-107.

Deser, C., 2000: On the teleconnectivity of the "Arctic Oscillation." Geophys. Res. Lett., 27, 779-782.

Dong, B., R. T. Sutton, and T. Woollings, 2010: Changes of interannual NAO variability in response to greenhouse gases forcing. Climate Dyn., 35, 1621-1641, doi:10.1007/s00382-010-0936-6.

Fitzpatrick, E. A., and A. Krishnan, 1967: A first-order Markov model for assessing rainfall discontinuity in central Australia. Theor. Appl. Climatol., 15, 242-259.

Frei, C., J. H. Christensen, M. Déqué, D. Jacob, R. G. Jones, and P. L. Vidale, 2003: Daily precipitation statistics in regional climate models: Evaluation and intercomparison for the European Alps. J. Geophys. Res., 108, 4124, doi:10.1029/2002JD002287.

Gallus, W. A., and M. Segal, 2004: Does increased predicted warmseason rainfall indicate enhanced likelihood of rain occurrence? Wea. Forecasting, 19, 1127-1135.

Han, J., and J. O. Roads, 2004: U. S. climate sensitivity simulated with the NCEP regional spectral model. Climatic Change, 62, 115-154.

Hayhoe, K., and Coauthors, 2007: Past and future changes in climate and hydrological indicators in the US Northeast. Climate Dyn., 28, 381-407.

Hershfield, D. M., 1971: The frequency of dry periods in Maryland. Chesap. Sci., 12, 72-84.

Hewitson, B. C., and R. G. Crane, 2006: Consensus between GCM climate change projections with empirical downscaling: precipitation downscaling over South Africa. Int. J. Climatol., 26, 1315-1337.

Houghton, J. T., and Coauthors, Eds., 2001: Climate Change 2001: The Scientific Basis. Cambridge University Press, 881 pp.

Hurrell, J. W., 1995: Decadal trends in the North Atlantic Oscillation: Regional temperatures and precipitation. Science, 269, 676-679.

_, Y. Kushnir, G. Ottersen, and M. Visbeck, 2003: An overview of the North Atlantic Oscillation. The North Atlantic Oscillation: Climatic Significance and Environmental Impact, Geophys. Monogr., Vol. 134, Amer. Geophys. Union, 1-35.

Jones, P. D., T. Jonsson, and D. Wheeler, 1997: Extension to North Atlantic Oscillation using early instrumental pressure observations from Gibraltar and South-West Iceland. Int. J. Climatol., 17, 1433-1450.

Kohonen, T., 1989: Self-Organization and Associative Memory. 3rd ed. Springer-Verlag, $312 \mathrm{pp}$.

_ 1995: Self-Organizing Maps. Spring-Verlag, 501 pp.

Li, W., L. Li, R. Fu, Y. Deng, and H. Wang, 2011: Changes to the North Atlantic Subtropical High and its role in the intensification of summer precipitation variability in the southeastern United States. J. Climate, 24, 1499-1506.

López-Moreno, J. I., and S. M. Vicente-Serrano, 2008: Positive and negative phases of the wintertime North Atlantic Oscillation and drought occurrence over Europe: A multitemporal-scale approach. J. Climate, 21, 1220-1243.

Maraun, D., and Coauthors, 2010: Precipitation downscaling under climate change: Recent development to bridge the gap between dynamical models and the end user. Rev. Geophys., 48 , RG3003, doi:10.1029/2009RG000314.

Meehl, G. A., and Coauthors, 2007: Global climate projections. Climate Change 2007: The Physical Science Basis, S. Solomon et al., Eds., Cambridge University Press, 747-845.

Miettinen, A., N. Koc, I. R. Hall, F. Godtliebsen, and D. Divine, 2011: North Atlantic sea surface temperatures and their relation 
to the North Atlantic Oscillation during the last 230 years. Climate Dyn., 36, 533-543.

Miller, R. L., G. A. Schmidt, and D. T. Shindell, 2006: Forced annular variations in the 20th century Intergovernmental Panel on Climate Change Fourth Assessment Report models. J. Geophys. Res., 111, D18101, doi:10.1029/2005JD006323.

Ning, L., and Y. Qian, 2009: Interdecadal change of extreme precipitation over South China and its mechanism. Adv. Atmos. Sci., 26, 109-118.

— M. E. Mann, R. Crane, and T. Wagener, 2012: Probabilistic projections of climate change for the mid-Atlantic region of the United States-Validation of precipitation downscaling during the historical era. J. Climate, 25, 509-526.

Plummer, D. A., and Coauthors, 2006: Climate and climate change over North America as simulated by the Canadian RCM. J. Climate, 19, 3112-3132.

Randall, D. A., and Coauthors, 2007: Climate models and their evaluation. Climate Change 2007: The Physical Science Basis, S. Solomon et al., Eds., Cambridge University Press, 589-662.

Rodó, X., E. Baert, and F. A. Comin, 1997: Variations in seasonal rainfall in southern Europe during the present century: Relationships with the North Atlantic Oscillation and the El Niño-Southern Oscillation. Climate Dyn., 13, 275 284.

Rowell, D. P., 2005: A scenario of European climate change for the late 21st century: Seasonal means and interannual variability. Climate Dyn., 25, 837-849.

_ , and R. G. Jones, 2006: Causes and uncertainty of future summer drying over Europe. Climate Dyn., 27, 281-299.

Shortle, J., and Coauthors, 2009: Pennsylvania climate impact assessment. Report to the Department of Environmental
Protection. Environment and Natural Resources Institute, The Pennsylvania State University Rep. 7000-BK-DEP4252, $350 \mathrm{pp}$.

Singh, R., T. Wagener, K. van Werkhoven, M. E. Mann, and R. Crane, 2011: A trading-space-for-time approach to probabilistic continuous streamflow predictions in a changing climate - Accounting for changing watershed behavior. Hydrol. Earth Syst. Sci., 15, 3591-3603.

Tebaldi, C., K. Hayhoe, J. M. Arblaster, and G. A. Meehl, 2006: Going to the extremes: An intercomparison of model-simulated historical and future changes in extreme events. Climatic Change, 79, 185-211.

Thompson, D. W. J., and J. M. Wallace, 2001: Regional climate impacts of the Northern Hemisphere annual mode. Science, 293, 85-89.

Trenberth, K. E., and Coauthors, 2007: Observations: Surface and atmospheric climate change. Climate Change 2007: The Physical Science Basis, S. Solomon et al., Eds., Cambridge University Press, 235-336.

Wagener, T., and Coauthors, 2010: The future of hydrology: An evolving science for a changing world. Water Resour. Res., 46, W05301, doi:10.1029/2009WR008906.

Wallace, J. M., and D. S. Gutzler, 1981: Teleconnections in the geopotential height field during the Northern Hemisphere winter. Mon. Wea. Rev., 109, 784-812.

Wanner, H., S. Brönnimann, C. Casty, D. Gyalistras, J. Luterbacher, C. Schmutz, D. B. Stephenson, and L. Xoplaki, 2001: North Atlantic Oscillation-Concepts and studies. Surv. Geophys., 22, 321-382.

Yin, J. H., 2005: A consistent poleward shift of the storm tracks in simulations of 21 st century climate. Geophys. Res. Lett., 32, L18701, doi:10.1029/2005GL023684. 